\title{
SLN melanoma micrometastasis predictivity of nodal status: a long term retrospective study
}

\author{
Emilia Migliano ${ }^{1 *}$, Barbara Bellei ${ }^{2}$, Flavio Andrea Govoni ${ }^{3}$, Giovanni Paolino ${ }^{4}$, Caterina Catricalà ${ }^{5}$ \\ Stefania Bucher ${ }^{1}$ and Pietro Donati ${ }^{4}$
}

\begin{abstract}
Background: Completion lymph node dissection (CLND) is the gold standard treatment for patients with a positive sentinel lymph node (SLN) biopsy. Considering the morbidity associated with CLND it is important to identify histological features of the primary tumor and/or of SLN metastasis that could help to spare from CLND a subset of patients who have a very low risk of non-SLN metastasis. The objective of this study is to identify patients with a very low risk to develop non-SLNs recurrences and to limit unnecessary CLND.

Methods: A retrospective long-term study of 80 melanoma patients with positive SLN, undergone CLND, was assessed to define the risk of additional metastasis in the regional nodal basin, on the basis of intranodal distribution of metastatic cells, using the micro-morphometric analysis (Starz classification).

Results: This study demonstrates that among the demographic and pathologic features of primary melanoma and of SLN only the Starz classification shows prognostic significance for non-SLN status $(p<0.0001)$. This parameter was also significantly associated with disease-free survival rate $(p<0.0013)$.

Conclusion: The Starz classification can help to identify, among SLN positive patients, those who can have a real benefit from CLND. From the clinical point of view this easy and reliable method could lead to a significant reduction of unnecessary CLND in association with a substantial decrease in morbidity. The study results indicate that most of S1 subgroup patients might be safely spared from completion lymphatic node dissection.

Furthermore, our experience demonstrated that Starz classification of SLN is a safe predictive index for patient stratification and treatment planning.
\end{abstract}

Keywords: Sentinel lymph node, SLN, CLND, Starz classification, Melanoma micrometastasis, Nodal status

\section{Introduction}

The sentinel lymph node (SLN) is the first lymph node reached by metastasizing cancer cells from a primary tumor. The lymphatic metastasis in melanoma always proceed sequentially involving cancer cell spreading from the primary site to regional nodes then to distant sites. In 1992 Morton et al. have demonstrated that it is rare that melanoma cells skip the sentinel lymph node and metastasize in other nodes [1]. Consequently, since its introduction into clinical practice, SLN biopsy has become a widely accepted procedure for predicting the status of regional lymph nodes $[2,3]$. The presence of SLN metastases

\footnotetext{
*Correspondence: migliano@ifo.it

'Department of Plastic and Reconstructive Surgery, San Gallicano

Dermatologic Institute, Rome, Italy

Full list of author information is available at the end of the article
}

is the strongest prognostic factor for melanoma and the histological status of the sentinel node has repeatedly shown to provide excellent prognostic information with respect to cancer spreading, disease-free and overall survival rate [4]. Current standards of practice suggest completion lymphatic node dissection (CLND) for all the patients with a positive SLN, whereas patients with negative SLN are considered to be at lowest risk of further lymph node extension. CLND aims to increase the local control of disease, survival improvement as well as staging patients. However, several studies have also demonstrated that only $20 \%$ of patients with a positive SLN will have further (Non-SLN) metastasis at CLND [5,6]. Although the impact of early dissection of subclinical micrometastatic nodes is well documented on the overall survival rate [7-9], most of the patients don't present nodal involvement.

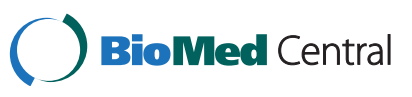


Moreover, considering the morbidity associated with CLND (paresthesias, wound infection, seroma and lymphoedema) it will be important to identify histological features of the primary tumour and/or of SLN metastases that could help to spare from CLND a subset of patients who are unlike to have metastatic non-SLNs and thus will not take any benefit from further nodal dissection.

The Starz classification is a micromorphometric analysis of the SLNs based on two parameters: the number of SLN slices, that contained melanoma cells, and the maximum depth of cellular invasion, measured as the maximum distance in millimetres between intra-nodal tumour cells and the inner margin of SLN capsule [8].

Our study was designed to define the risk of additional metastasis in the regional nodal basin on the basis of SLN micro-morphometric study, in order to identify patients with the lowest risk of tumour metastasis in NSLNs. Moreover, we retrospectively evaluated the disease-free survival (DFS) rate and the overall survival (OS) rate of patients, considering several clinical and pathological aspects of primary melanoma compared with the findings of micromorphometric analysis performed on the excised lymphatic nodes.

\section{Methods}

\section{Patients}

Between 2000 and 2005, 537 consecutive patients with primary cutaneous melanoma that underwent to SLN biopsies were identified from a prospectively maintained departmental database comprising 685 patients. Among these, 100 SLN positive patients (18.6\%) subsequently undergone to CLND were initially enrolled for this study. However, the availability of the original specimens for histopathologic reexamination and a full documented post-operative period (at least five years) restricted the patient group to 80 subjects. All data from patients undergone sentinel lymph node biopsy, regardless of gender, age and localizations were retrieved from the pathology database of Dept. of Plastic Surgery and of the Dept. of Dermatopathology of the "Dermatological Institute San Gallicano" of Rome, comprising more than 900 patients from a 13-years period (19972010). To obtain a full post-operative period of at least five years we selected 80 subjects showing positive SLN treated between 2000 and 2005. Most patients were followed in the Departments of Plastic Surgery and the data concerning their evolution were available in their medical records. For those who interrupted their follow-up, the physician in charge of follow-up was interviewed systematically to get the latest status. Survival was calculated from the date of the initial excision of the primary tumor.

\section{SLN procedure}

All patients underwent preoperative lymphoscintigraphy to ascertain the number and location of regional nodal basins at risk for metastatic disease. The lymphoscintigraphy was performed the day before or the same day of surgery by intradermal injection of technetium-99labeled nanocolloid. Under a general anaesthesia or neuroleptanalgesia, blue patent $\mathrm{V}(0.5-1 \mathrm{ml})$ was injected intradermally around the excisional scar. Sentinel lymph nodes were identified intraoperatively by their blue colour and radioactivity detected with hand-held gamma probe. All blue nodes and all radioactive nodes (hottest) were considered sentinel and were removed. All patients presenting a positive SLN underwent within four weeks to a CLND.

\section{Histopathological examination}

SLNs were fixed in $4.5 \%$ formaldehyde for 24 hours. Then three-dimensional measurement and macroscopic characteristics were evaluated for every lymph node. Lymph nodes were cut parallel to the longest axis into slices about $1 \mathrm{~mm}$ thickness and embedded in paraffin blocks. Four sections ( $3 \mu \mathrm{m}$ thick) of each slice were produced with a microtome: the first one was stained with haematoxylineosin, and the subsequent for the immuno-hystochemistry with S100, HMB45 and MART1 antibodies $[9,10]$.

\section{Starz staging}

According to the Starz classification $[8,11,12]$ all patients were divided into three categories based on the number of positive sections $(n)$ and the maximum distance from the interior margin of the biggest metastatic group to the capsule of the SN $(d)$ as follows: S1 for peripheral involvement $(1<n<2$ and $d<0.3 \mathrm{~mm}), \mathrm{S} 2$ for extended or multifocal involvement $(n>2$ and $0.3<d<1 \mathrm{~mm})$ and S3 classifying metastatic invasion deeper than $1 \mathrm{~mm}$ below the capsular level $(d>1 \mathrm{~mm})[8,11,12]$.

\section{Statistical analysis}

An independent biostatistician performed statistical evaluation. Patient's characteristics included: demographic data (age and sex) and histological features of the primary melanoma (Breslow thickness, Clark level, ulceration and histological subtype); while for the sentinel lymph node included the number of sentinel lymph node removed, the pattern of invasion and the invasion depth of metastatic cells in the sentinel lymph node (Starz Classification). For statistical analysis parametric tests were applied: Hazard Ratio and 95\% Confidence Interval were used to study the test and overall survival rate. Kaplan-Meier curves were used to estimate significance in OS differences. Significance for all statistical tests was defined as p values $<0.005$.

\section{Results}

In this study we have enrolled 80 patients, 46 (57\%) were males and $34(43 \%)$ were females (mean age 48 years; range of 20-83 years). The mean Breslow 


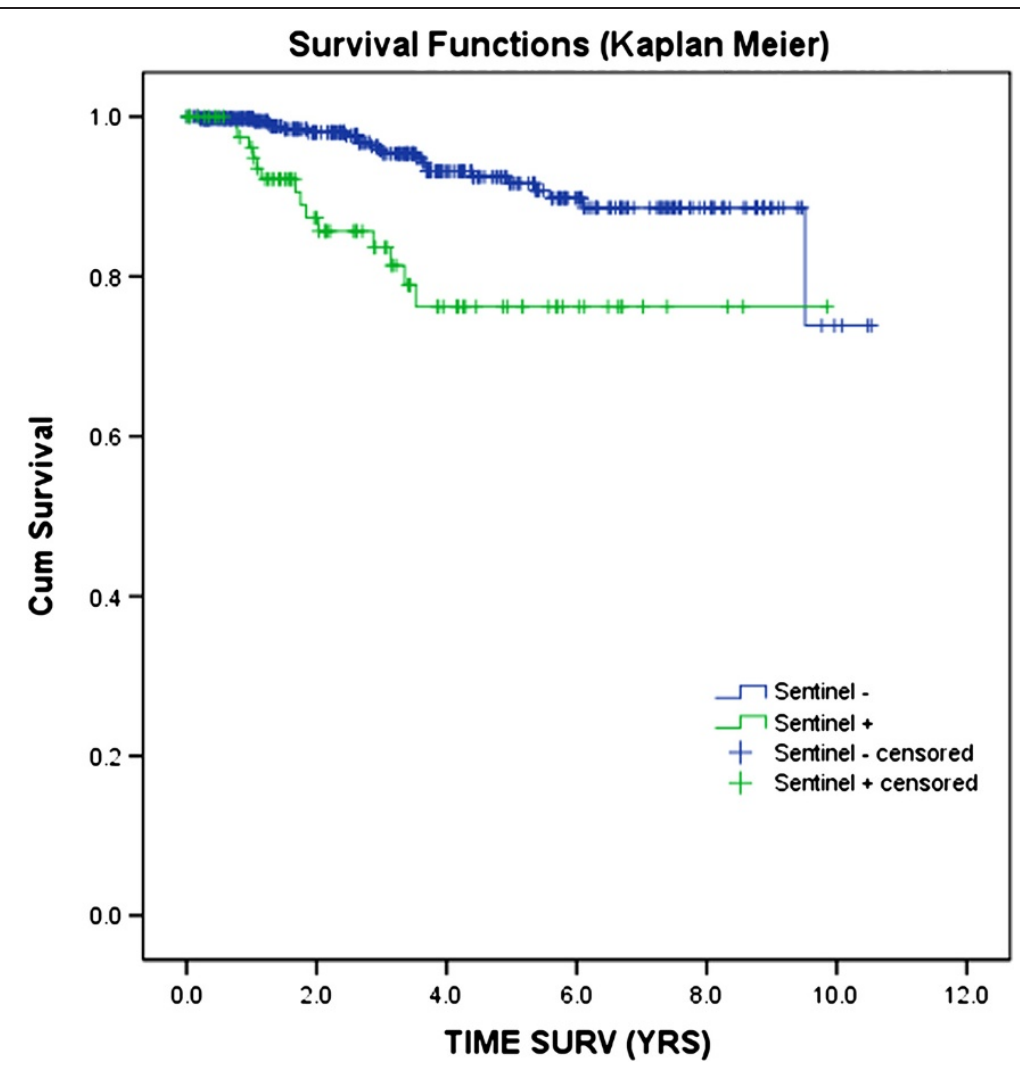

Figure 1 Kaplan-Meier survival curve for patients undergoing successful CLND. The ten-years overall survival (OS) showed a significant shorten survival in SLN-positive patients than in SLN-negative patients ( $p<0.0001)$. Mean survival time $(8.01 \pm 0.44$ yrs for SLN + and $9.61 \pm 0.21$ yrs for SLN-).

thickness of the primary melanoma was of $3.0 \mathrm{~mm}$ (range 0.4-6.0 mm); 3 patients $(4 \%)$ were of Clark II, $21(26 \%)$ were of Clark III, $52(65 \%)$ were of Clark IV and $4(5 \%)$ of Clark V. Melanoma subtype included nodular (36\%), superficial spreading (47\%), and polypoid (17\%). More than half of the tumors were ulcerated (51\%). Regarding the regional distribution of SLN biopsies 36 were axillary (45\%), 32 groin $(40 \%), 8(10 \%)$ present a double basin (7axillary +groin and 1 axillary+supraclavear), and 4 of the neck (5\%). CLND found at least one positive nonSLN in 15 cases (19\%). The median follow-up was 78 months (range 60-120 months). During the followup period only 5 patients (6\%) had a loco-regional

Table 1 Results for number of excised SLN

\begin{tabular}{lcc}
\hline EXCISED SLN (N) & N Patients & $\%$ \\
\hline 1 & 9 & $11 \%$ \\
2 & 24 & $30 \%$ \\
3 & 38 & $48 \%$ \\
$>3$ & 9 & $11 \%$ \\
\hline
\end{tabular}

recurrence. From the 80 enrolled cases, 69 (86\%) were alive without evidence of disease at the time of this writing. According with the literature, Kaplan Meier curve, used to evaluate overall survival (OS), showed a significant shorten survival in SLN-positive patients than in SLN-negative patients $(\mathrm{p}<0.0001$; chi-square test) (Figure 1). To better analyze the data, patients were divided according to the number of lymph nodes excised after finding micromorphometric metastasis in SLN. In particular, in 9 patients $(11 \%)$ were excised only one lymph node, in 24 patients $(30 \%)$ were excised two lymph nodes, in 38 patients (48\%) were excised three lymph nodes while in $9(11 \%)$ were excised more than 3 lymph

Table 2 Results for number of positive SLN

\begin{tabular}{lcc}
\hline DISEASE-POSITIVE SLN (N) & N Patients & $\%$ \\
\hline 1 & 47 & $59 \%$ \\
2 & 15 & $19 \%$ \\
3 & 12 & $15 \%$ \\
$>3$ & 6 & $7 \%$ \\
\hline
\end{tabular}


Table 3 Results of S-classification for patients in this study

\begin{tabular}{lcc}
\hline S-classification & N Patients & $\%$ \\
\hline S1 & 40 & $50 \%$ \\
S2 & 15 & $19 \%$ \\
S3 & 25 & $31 \%$ \\
\hline
\end{tabular}

nodes (Table 1). Patients were also divided further by the number of positive NSLNs: 47 patients (59\%) presented one positive lymph node, 15 patients (19\%) two positive lymph nodes, 12 patients (15\%) presented 3 positive lymph nodes whereas for 6 patients $(7 \%)$ the positive lymph nodes were more than 3 (Table 2).

Regarding the Starz classification we found that 40 patients (50\%) were classified as S1, 15 (19\%) as S2 and 25 (31\%) as S3 (Table 3). In patients without NSLNs involvement, 40 SLNs (61\%) were classified as S1, 9 (14\%) as S2, while 16 SLNs (25\%) were classified as S3. On the other hand, in NSLNs with metastasis, we reported 9 SLNs (60\%) were classified as S3 and 6 SLNs (40\%) were classified as S2. None of the 40 patients of the S1 group presented NSLN metastasis. The occurrence of at least one melanoma-positive non-SLN significantly increased from 0 (of 40 in S1 SLNs) to 6 (of 15 in S2 SLNs) up to 9 (of 25 in S3 SLNs) ( $\mathrm{p}=0.0124$; chi-square test). Moreover, it is important to highlight that among the parameters studied the univariate analysis indicated a significant association of NSLNs metastasis only with the Starz classification ( $\mathrm{p}<0.0001$; chi-square test) (Table 4$)$. The mean Breslow thickness was $2.6 \mathrm{~mm}$ for S1 group, $2.8 \mathrm{~mm}$ for the S2 group, and $3.9 \mathrm{~mm}$ for the S3 group. The highest percentage of ulcerated primary tumor was found in the S3 patients group (S1 56\%, S2 40\%, S3 83\%). Concerning the distribution of melanoma subtypes we found: in the S1 group 24 of $40(60 \%)$ were SSM, 11 of 40 (27.5\%) nodular and 5 of $40(12.5 \%)$ polypoid; in the S2 group 8 of 15 (54\%) were SSM, 5 of 15 (33\%) nodular, 2 of 15 (13\%) polypoid; in the S3 group 4 of 25 (16\%) were SSM, 14 of 25 (56\%) nodular and 7 of 25 (28\%) polypoid. Distant metastasis were present in 2 patients S1 (5\%), in 2 patients S2 (13\%) and in 2 patients with S3 (8\%). Sclassification results are summarized in Table 5 . The univariate analysis of disease-free survival (DFS) showed no significant association with the variables considered in the study (sex, age, Breslow thickness, and number of positive SLNs) with the exception of S-classification (OR 7.4 [95\% CI 1.94, 28.24]; $\mathrm{p}=0.013$; chi-square test) (Table 6). The overall OS rate was $86 \%$, among the 11 patients dead we observed the following distribution: in the S1 group 3 of 40 patients $(7,5 \%)$, in the S2 group 2 of 15 patients (13\%), and in the S3 group 6 of 25 patients (24\%). The OS analysis showed significant association only with the Breslow thickness (OR 3.08 [95\% CI 0.75, 12.61]; p=0.002) (Table 7).

\section{Discussion}

Negative SLN biopsy findings are well known prognostic factors. Other ways, the positivity to a SLN biopsy lead the patient to a completion lymph node dissection (CLND)

Table 4 Univariate analysis of sex, age, Breslow thickness, number of positive lymph nodes and S-classification

\begin{tabular}{|c|c|c|c|c|c|c|}
\hline & \multicolumn{2}{|c|}{ Disease-negative CLND ( $n=15)$} & \multicolumn{3}{|c|}{ Disease-positive CLND $(n=15)$} & \multirow{2}{*}{$\begin{array}{c}\text { univivariate analysi } \\
\text { P value }\end{array}$} \\
\hline & No & $\%$ & No & & $\%$ & \\
\hline \multicolumn{7}{|l|}{ SEX } \\
\hline male & 39 & $60 \%$ & 7 & & $47 \%$ & 0.346 \\
\hline female & 26 & $40 \%$ & 8 & & $53 \%$ & \\
\hline \multicolumn{7}{|l|}{ AGE } \\
\hline Mean \pm SD & & $48.5 \pm 16.3$ & & $47.9 \pm 11.9$ & & 0.880 \\
\hline Range & & $20-83$ & & $30-67$ & & \\
\hline \multicolumn{7}{|c|}{ BRESLOW THICKNESS } \\
\hline Mean \pm SD & & $2.8 \pm 1.2$ & & $2.7 \pm 1.4$ & & 0.744 \\
\hline Range & & $1.0-6.0$ & & $0.4-4.1$ & & \\
\hline \multicolumn{7}{|c|}{$\mathrm{N}$ of positive SLN } \\
\hline 1 & 46 & $71 \%$ & 13 & & $87 \%$ & 0.207 \\
\hline$>1$ & 19 & $29 \%$ & 2 & & $13 \%$ & \\
\hline \multicolumn{7}{|c|}{ STARZ CLASSIFICATION } \\
\hline S1 & 40 & $61 \%$ & 0 & & $0 \%$ & 0.0001 \\
\hline S2 & 9 & $14 \%$ & 9 & & $40 \%$ & \\
\hline S3 & 16 & $25 \%$ & 6 & & $60 \%$ & \\
\hline
\end{tabular}


Table 5 Tumour characteristics of 80 patients with cutaneous melanoma who underwent CLND divided according to the S-classification

\begin{tabular}{|c|c|c|c|c|c|c|c|c|}
\hline \multicolumn{9}{|c|}{ Histologic type } \\
\hline S-group & Ulceration \% & Breslow (mm) & SSM \% & Nodular $\%$ & Polipoid \% & CNLD + \% & Distal Mestastasis \% & Death \\
\hline S1 & $56 \%$ & 2.6 & $60 \%$ & $27.5 \%$ & $12.5 \%$ & $0 \%$ & $5 \%$ & $7.5 \%$ \\
\hline S2 & $40 \%$ & 2.8 & $54 \%$ & $33 \%$ & $13 \%$ & $40 \%$ & $13 \%$ & $13 \%$ \\
\hline S3 & $83 \%$ & 3.9 & $16 \%$ & $56 \%$ & $28 \%$ & $36 \%$ & $8 \%$ & $24 \%$ \\
\hline
\end{tabular}

and approximately the $35 \%-50 \%$ of SLN positive patients die within 5 years [13-15]. Morton et al. demonstrated a highly significant survival benefit in SLN-positive patients who had received CLND (5-year survival rate 72\%) compared to SLN-positive patients who had received delayed ELND (Elective LND) after clinical detection of lymph node metastasis (5-year survival rate 52\%) [16].

However, at the moment, there is no consensus on the benefit of a completion dissection in melanoma patients. As reported in literature, only the $14 \%-18 \%$ of positive patients will harbour further disease in the affected basin [14-17]. Only patients with secondary involvement in NSLNs find benefit in a CLND while a large percentage of patients (NSLNs negative) will increase only the morbidity rate due to this surgical procedure [18]. In this respect it will be of primary importance to identify histological biomarkers (relative to patient, tumour, and SNL characteristics) that can safely predict an additional risk of NSLN recurrence in SLN positive patients. In this way we will be able to increase the disease-free survival and the overall survival rate lowering at the same time the morbidity rate. In our opinion the key point would be to recommend CLND only to those patients who have an high predictive risk of NSLN positivity, using a patient selection criteria as currently stated in the treatment of breast cancer, where patients with sub-

Table 6 Disease free survival analysis

\begin{tabular}{|c|c|c|c|}
\hline \multicolumn{4}{|c|}{ DISEASE-FREE SURVIVAL RATE } \\
\hline & HR & 95\% C.I. & $P$ value \\
\hline \multicolumn{4}{|l|}{ SEX } \\
\hline Male & 1 & & \\
\hline Female & 3.28 & $0.366-29.455$ & 0.288 \\
\hline $\operatorname{Age}(Y)^{*}$ & 1.004 & $0.950-1.062$ & 0.874 \\
\hline Breslow $(\mathrm{mm})^{*}$ & 3.16 & $0.678-11.517$ & 0.081 \\
\hline \multicolumn{4}{|l|}{ No positive SLN } \\
\hline 1 & 1 & & \\
\hline$>1$ & 1.672 & $0.279-10.006$ & 0.54 \\
\hline \multicolumn{4}{|c|}{ STARZ CLASSIFICATION } \\
\hline S1 & 1 & & \\
\hline S2-S3 & 7.4 & $1.938-28.244$ & 0.0013 \\
\hline
\end{tabular}

C.I. confidential interval, $H R$ Harzard ratio, *as continuous variable. micrometastasis $(<0.2 \mathrm{~mm})$ in the SLN are spared from axillary CLND, due to the very low risk of nodal recurrence [19-22]. In melanoma the Breslow thickness and the ulceration of the primary tumour, the number of positive SLNs and tumour penetrative depth inside the SLN are significant prognostic factors of high risk NSLNs positivity $[14,15,22-26]$. However, statistical data reviewed from the literature on these factors are still very poor so that currently none of these parameters can give a safe a reliable prognostic indication on NSLNs status. Previous studies have shown that several characteristics of deposits of metastatic melanoma in SLNs correlate with the presence of tumour in NSLNs in subsequent CLND specimens [17,21-24]. In our study, the microanatomic features of the SLNs metastasis, particularly the tumour penetrative depth of the deposit (according with Starz classification) and several clinicpathologic data were analyzed looking for a predictive marker for NSLN involvement. Among 80 cases underwent CLND, 15 patients (19\%) had NSLN positivity, while the remaining 65 (81\%) had no metastases, according to the data reviewed from the literature [13,14,18,27-30]. Patients presenting a positive CLND were all classified as S2 or S3 at the SLN histological micro-morphometric analysis confirming that Starz classification is an indicative factor of high risk of regional

Table 7 Overall survival analysis

\begin{tabular}{lccc}
\hline \multicolumn{4}{c}{ OVERALL SURVIVAL RATE } \\
\hline & HR & $\mathbf{9 5 \%}$ C.I. & Pvalue \\
\hline SEX & 1 & & \\
Male & 1.692 & $0.588-4.867$ & 0.33 \\
Female & 1.02 & $0.986-1.055$ & 0.244 \\
Age(Y)* & 7.42 & $2.031-27.119$ & $\mathbf{0 . 0 0 2}$ \\
Breslow(mm)* & & & \\
No Positive SLN & 1 & & \\
1 & 1.727 & $0.576-5.179$ & 0.33 \\
>1 & & & \\
STARZ CLASSIFICATION & 1 & & \\
S1 & 3.083 & $0.753-12.613$ & 0.104 \\
\hline S2-S3 & & &
\end{tabular}

C.I. confidential interval, HR Harzard ratio, *as continuous variable. 
nodal recurrence. (Table. $6 ; p$ value $=0,0013$.) The evaluation of "median primary tumour thickness" factor resulted, in our study, not statistically significant ( $p$ value $=0.7436$ ) on NSLNs metastasis, but well correlated to the OS (overall survival rate - Table 7; $p$ value $=0,02$ ). The predictive value of "tumour ulceration" factor on NSLN involvement has been found in some previous studies, but not confirmed by others, thus indicating a great deal of variability which limits the drawing of definite conclusions [31-38]. In our study, the ulceration of primary lesion was present in 41 patients (51\%). Evaluating ulceration factor in S-subgroups $56 \%$ of S1, $40 \%$ of S2 and $83 \%$ of S3 patients had ulcerated lesions. Among the 11 patients who died for melanoma metastasis the ulceration factor was present in 9 (81\%). It is interesting to note that inside the group of died patients 6 (55\%) were classified as S3, 2 (18\%) as S2 and $3(27 \%)$ as S1. The analysis of S1 dead patients revealed that everyone presented peculiar characteristics: one patient had two different SLN compromised, another patient presented severe ulceration of the primary lesion, while the third patient had an high Breslow thickness, nodular type, primary melanoma. These results outline the relevance of clinical biomarkers that can be useful, in correlation to the histological markers, to predict S1 patients clinical outcome. It should be reported, that Reeves et al. [26] proposed the ratio size of metastases on SLN/ulceration (S/U score) as predictor factor of NSLNs status, while Frankel et al. [27] utilized the relation between the thickness of primary tumour and the surface area, measured in percentage, of the metastases on SLN.

According with previous studies [2,14,16,17,27] and the recent study of Nagaraja [38], where it is shown a very accurate and extensive meta-analysis involving several predictive factors to determine the risk of lymph node metastasis, our data confirmed that about $20 \%$ of SLN positive patients undergone CLND present an additional lymphatic involvement. At the moment, according to the staging guidelines of the American Joint Committee on Cancer (AJCC) the most important prognostic factor in patients affected by melanoma is the SLN status [28-31]. The current standard treatment for SLN positive patients is the completion lymphatic node dissection. Within the last few years, several studies have been conducted to determine whether some patients could be classified as low risk of further nodal metastasis according to the type of involvement of the SLN. Furthermore, the overall data published $[11,16,21,29]$ and the present study evidenced that the prognosis of patients is determined not only by the presence of melanoma cells in SLNs but also by a micromorphometric characterization of SLNs according to the Starz classification. On these bases some Authors suggested the possibility to avoid the CLND to a subgroup of selected patients [30-34]. Already in few centres, patients with SLN tumour deposits $<0.1 \mathrm{~mm}$ in maximal dimension can choose if undergo CLND or clinical nodal follow-up [16,18,33-38]. In our report, using univariate analysis, we confirmed the prognostic relevance of Starz classification suggesting that patients classified as S1 could safely spare to the CLND. None of S1 patients presented CLND positivity, suggesting that the increased morbidity associated with complete nodal dissection could be avoided in this group of patients. Moreover, the DFS of S1 patients was significantly higher than S2-S3 patients (p value 0.0013 ).

In conclusion, our results showed that, among the 80 SLN positive melanoma patients studied, 65 (81\%) underwent to CLND in absence of an evident benefit but increasing only the morbidity. NSLNs metastases were found only in 15 patients (19\%). None of the S1 patient had positive NSLN. Considering that we recorded three dead patients among the S1 subgroup in absence of NSLN involvement, our future study will aim to select important biomarkers that, in combination with S-classification, could help to select a S1 subgroup presenting major risk of disease progression. Interestingly, while this research was in progress, Veenstra et al., reported a positive 5-years experience for 16 melanoma patients classified as Starz level 1 that did not undergo completion lymphatic node dissection [33]. Although further investigations are needed, on larger and multicentric studies, we think that our observations can contribute to suggest the way to find a clinically reliable technique (i.e. an algorithm of the mentioned factors), and an easy application method to identify, among melanoma patients, those who present the higher risk of NSLN recurrence [37,38]. In our opinion this selection will provide a more accurate depiction of prognosis and will help to define subsequent recommendations for the treatment and the follow-up care.

\section{Competing interest}

The authors declare that they have no competing interest.

\section{Authors' contributions}

EM was the research leader, conceived the study, collected the clinical informations, drafted and revised the manuscript. BB and GP participated in clinical data collection-analysis and in manuscript drafting. FAG performed the critical revision of the research data and participated in the writing of the final manuscript. CC and SB contributed to the financial support of the research and were involved in the final approval of the manuscript. PD performed the revision of all histopathological and immuno-hystochemical examinations included in this research. All the authors read and approved the manuscript.

\section{Acknowledgement}

We wish to thank Dr. Francesca De Terlizzi for statistical analysis, Mr. Marco Zaccarini for histological technical assistance, and Mr. Umberto Santi for sentinel data-base creation and software assistance.

\section{Funding sources}

IRCCS San Gallicano-Scientific Research Direction - Roma (Italy). 


\section{Author details}

${ }^{1}$ Department of Plastic and Reconstructive Surgery, San Gallicano Dermatologic Institute, Rome, Italy. ${ }^{2}$ Laboratory of Cutaneous Physiopathology, San Gallicano Dermatologic Institute, Rome, Italy. ${ }^{3}$ Department of Maxillofacial Surgery, San Filippo Neri Hospital, Rome, Italy. ${ }^{4}$ Dermatopathology Unit, San Gallicano Dermatologic Institute, Rome, Italy. ${ }^{5}$ Department of Dermatology-Oncology, San Gallicano Dermatologic Institute, Rome, Italy.

\section{Received: 4 June 2013 Accepted: 26 July 2013}

Published: 1 August 2013

\section{References}

1. Morton DL, Wen DR, Wong JH, Economou JS, Cagle LA, Storm FK, Foshag U, Cochran AJ: Technical details of intraoperative lymphatic mapping for early stage melanoma. Arch Surg 1992, 27:392-399.

2. Thompson JF, McCarthy WH, Bosch CM, O'Brien CJ, Quinn MJ, Paramaesvaran S, Crotty K, McCharty SW, Uren RF, Howman-Giles R: Sentinel lymph node status as an indicator of the presence of metastatic melanoma in regional lymph nodes. Melanoma Res 1995, 5:255-260.

3. Gershenwald JE, Thompson W, Mansfield PF, Lee JE, Colome MI, Tseng CH, Lee JJ, Balch CM, Reintgen DS, Ross MI: Multi-institutional melanoma lymphatic mapping experience: the prognostic value of sentinel lymph node status in 612 stage I or II melanoma patients. J Clin Oncol 1999. 17:976-983

4. Cascinelli N, Belli F, Santinami M, Fait V, Testori A, Ruka W, Cavaliere R, Mozzillo N, Rossi CR, MacKie RM, Nieweg O, Pace M, Kirov K: Sentinel lymph node biopsy in cutaneous melanoma: the WHO Melanoma Program experience. Ann Surg Oncol 2000, 7:469-474.

5. Morton DL, Cochran AJ, Thompson JF, Elashoff R, Essner R, Glass EC, Mozzillo N, Nieweg OE, Roses DF, Hoekstra HJ, Karakousis CP, Reintgen DS, Coventry BJ, Wang H, Multicenter Selective Lymphadenectomy Trial Group: Sentinel node biopsy for early-stage melanoma: Accuracy and morbidity in MSLT-I, an international multicenter trial. Ann Surg 2005, 242:302-311. discussion 311-313.

6. Gershenwald JE, Andtbacka RH, Prieto VG, Johnson MM, Diwan AH, Lee JE, Mansfield PF, Cormier JN, Schacherer CW, Ross Ml: Microscopic tumor burden in non sentinel lymph nodes predicts synchronous non sentine lymph node involvement in patients with melanoma. J Clin Oncol 2008, 26:4296-4303.

7. Pasquali S, Mocellin S, Campana LG, Bonandini E, Montesco MC, Tregnaghi A, Del Fiore P, Nitti D, Rossi CR: Early (Sentinel Lymph Node BiopsyGuided) versus delayed lymphadenectomy in melanoma patients with lymph node metastases. Cancer 2010, 116:1201-1209.

8. Starz H, Siedleki K, Balda BR: Sentinel lymphadenectomy and Sclassification: a successful strategy for better prediction and improvement of outcome of melanoma. Ann Surg Oncol 2004, 11:162S-168S

9. Cochran AJ, Balda BR, Starz H, Bachter D, Krag DN, Cruse CW, Pijpers R, Morton DL: The Ausburg Consensus. Techniques of lymphatic mapping, sentinel lymphadenectomy, and Completion lymphadenectomy in cutaneous malignancies. Cancer 2000, 89:236-241.

10. Satzger I, Völker B, Meier A, Schenck F, Kapp A, Gutzmer R: Prognostic significance of isolated $\mathrm{HM} 45$ or melan A positive cells in melanoma sentinel lymph nodes. Am J Surg Pathol 2007, 31:1175-1180.

11. Starz H: Pathology of sentinel lymph node in melanoma. Semin Oncol 2004, 31:357-362.

12. Starz H, Balda BR, Kramer KU, Büchels $H$, Wang H: A micromorphometricbased concept for routine classification of sentinel lymph node metastases and its clinical relevance for patients with melanoma. Cancer 2001, 91:2110-2121.

13. Kunte C, Geimer T, Baumert J, Konz B, Volkenandt M, Flaig M, Ruzicka T, Berking C, Schmid-Wendtner MH: Analysis of predictive factors for the outcome of complete lymph node dissection in melanoma patients with metastatic sentinel lymph nodes. J Am Acad Dermatol 2011, 64:655-662.

14. van Akkooi AC, de Wilt JH, Verhoef C, Schmitz PI, van Geel AN, Eggermont AM, Kliffen M: Clinical relevance of melanoma micrometastases $(<0,1 \mathrm{~mm})$ in sentinel lymph node. Are these nodes to be considered negative? Ann Oncol 2006, 17:1578-1585.

15. Testori A, De Salvo G, Montesco MC, Trifirò G, Mocellin S, Landi G, Macripò G, Carcoforo P, Ricotti G, Giudice G, Picciotto F, Donner D, Di Filippo F,
Soteldo J, Casara D, Schiavon M, Vecchiato A, Pasquali S, Baldini F, Mazzarol G, Rossi CR, Italian Melanoma Intergroup: Clinical considerations on sentinel node biopsy in melanoma from an Italian multicentric study on 1313 Patients (SOLISM -IMI). Ann Surg Oncol 2009, 16(7):2018-2027.

16. Morton DL, Thompson JF, Cochran AJ, Mozzillo N, Elashoff R, Essner R, Nieweg OE, Roses DF, Hoekstra HJ, Karakousis CP, Reintgen DS, Coventry BJ, Glass EC, Wang HJ, MSLT Group: Sentinel-node biopsy or nodal observation in melanoma. N Engl J Med 2006, 335:1307-1317.

17. Quaglino P, Ribero S, Osella-Abate S, Macrì L, Grassi M, Caliendo V, Asioli S, Sapino A, Macripò G, Savoia P, Bernengo MG: Clinico-pathologic features of primary melanoma and sentinel lymph node predictive for nonsentinel lymph node involvement and overall survival in melanoma patients: a single centre observational cohort study. Surg Oncol 2010, 20:259-264

18. Rossi CR, De Salvo GL, Bonandini E, Mocellin S, Foletto M, Pasquali S, Pilati P, Lise M, Nitti D, Rizzo E, Montesco MC: Factors predictive of nonsentine lymph node involvement and clinical outcome in melanoma patients with metastatic sentinel lymph node. Ann Surg Oncol 2008, 15:1202-1208.

19. Fournier K, Schiller A, Perry RR, Laronga C: Micrometastasis in the sentinel lymph node of breast cancer cancer does not mandate completion axillary dissection. Ann Surg 2004, 239:859-863.

20. Rutgers EJ: Sentinel node micrometastasis in breast cancer. Br J Surg 2004, 91:1241-1242

21. Dewar DJ, Newell B, Green MA, Topping AP, Powell BW, Cook MG: The microanatomic location of metastatic melanoma in sentinel lymph nodes predicts non-sentinel lymph node involvement. J Clin Oncol 2004, 22:3345-3349.

22. Roka F, Mastan P, Binder M, Okamoto I, Mittlboeck M, Horvat R, Pehamberger $\mathrm{H}$, Diem E: Prediction of non-sentinel node status and outcome in sentinel node-positive melanoma patients. Eur J Surg Oncol 2008, 34:82-88.

23. Cochran AJ, Wen DR, Huang RR, Wang HJ, Elashoff R, Morton DL: Prediction of metastatic melanoma in non-sentinel nodes and clinical outcome based on the primary melanoma and the sentinel node. Mod Pathol 2004, 17:747-755.

24. Wagner JD, Gordon MS, Chuang TY, Coleman JJ 3rd, Hayes JT, Jung SH, Love C: Predicting sentinel and residual lymph node basin disease after sentinel lymph node biopsy for melanoma. Cancer 2000, 89:453-462.

25. Sabel MS, Griffith K, Sondak VK: Predictors of non sentinel lymph node positivity in patients with a positives sentinel node for melanoma. J Am Coll Surg 2005, 201:37-47.

26. Reeves ME, Delgado R, Busam KJ, Brady MS, Coit DG: Prediction of nonsentinel lymph node status in melanoma. Ann Surg Oncol 2003, 10:27-31.

27. Frankel TL, Griffith KA, Lowe L, Wong SL, Bichakjian CK, Chang AE, Cimmino VM, Bradford CR, Rees RS, Johnson TM, Sabel MS: Do micromorphometric features of metastatic deposits within sentinel nodes predict non sentinel lymph node involvement in melanoma? Ann Surg Oncol 2008 15:2403-2411

28. van der Ploeg IM, Kroon BB, Antonini N, Valdés Olmos RA, Nieweg OE: Is completion lymph node dissection needed in case of minimal melanoma metastasis in the sentinel node? Ann Surg 2009, 249:1003-1007.

29. Van der Ploeg IM, Kroon BB, Antonini N, Valdés Olmos RA, Nieweg OE: Comparison of three micromorphometric pathology classifications of melanoma metastasis in the sentinel node. Ann Surg 2009, 250:301-304.

30. Bogenriender T, van Dijk MR, Bloky WA, Ramrath K, Seldenrijk K, Stolz W, van Diest PJ: No non-sentinel node involvement in melanoma patients with limited Breslow thickness and low sentinel node tumor load. Histopathol 2011, 59:318-326.

31. Balch CM, Gershenwald JE, Soong SJ, Thompson JF, Atkins MB, Byrd DR, Buzaid AC, Cochran AJ, Coit DG, Ding S, Eggermont AM, Flaherty KT Gimotty PA, Kirkwood JM, McMasters KM, Mihm MC Jr, Morton DL, Ross Mt, Sober AJ, Sondak VK: Final version of, 2009 AJCC melanoma staging and classification. J Clin Oncol 2009, 27:6199-6206.

32. Murali R, Cochran AJ, Cook MG, Hillman JD, Karim RZ, Moncrieff M, Starz H, Thompson JF, Scolyer RA: Inter-observer reproducibility of histologic parameters of melanoma deposits in sentinel lymph nodes: implications for management of patients with melanoma. Cancer 2009, 115:5026-5037.

33. Veenstra HJ, Brouwer OR, van der Ploeg IM, Kroon BB, Nieweg OE: Five-year follow-up of 16 melanoma patients with a Starz l-involved sentinel node 
in whom completion lymph node dissection was omitted. Melanoma Res 2012, 22(6):436-439.

34. Maio M, Ascierto P, Testori A, Ridolfi R, Bajetta E, Queirolo P, Guida M, Romanini A, Chiarion-Sileni V, Pigozzo J, Di Giacomo AM, Calandriello M, Didoni G, van Baardewijk M, Konto C, Lucioni C: The cost of unresectable stage III or stage IV melanoma in Italy. J Exp Clin Cancer Res 2012, 31:91.

35. Solivetti MF, Elia F, Graceffa D, Di Carlo A: Ultrasound morphology of inguinal lymph nodes may not herald an associated pathology. J Exp Clin Cancer Res 2012, 31:88.

36. Fabi A, Felici A, Metro G, Mirri A, Bria E, Telera S, Moscetti L, Russillo M, Lanzetta G, Mansueto G, Pace A, Maschio M, Vidiri A, Sperduti I, Cognetti F, Carapella CM: Brain metastases from solid tumors: disease outcome according to type of treatment and therapeutic resources of the treating center. J Exp Clin Cancer Res 2011, 30:10.

37. von Akooi AC, Verhoef C, Eggermont AM: Importance of tumor load in the sentinel node in melanoma: clinical dilemmas. Nat Rev Clin Oncol 2010, 7(8):446-454.

38. Nagaraja V, Eslick GD: Is complete lymph node dissection after a positive sentinel lymoh node biopsy for cutaneous melanoma always necessary? A meta-analysis. Eur J Surg Oncol 2013, 39(7):669-680.

doi:10.1186/1756-9966-32-47

Cite this article as: Migliano et al: SLN melanoma micrometastasis predictivity of nodal status: a long term retrospective study. Journal of Experimental \& Clinical Cancer Research 2013 32:47.

\section{Submit your next manuscript to BioMed Central and take full advantage of:}

- Convenient online submission

- Thorough peer review

- No space constraints or color figure charges

- Immediate publication on acceptance

- Inclusion in PubMed, CAS, Scopus and Google Scholar

- Research which is freely available for redistribution 